\title{
The Diagnostic Utility of Splenectomy in Idiopathic Splenomegaly
}

\author{
Valentina Palumbo $^{1} \cdot$ Marco Vitale $^{1} \cdot$ Adriana Toro $^{2} \cdot$ Isidoro Di Carlo $^{1}$
}

Accepted: 30 August 2020/Published online: 10 October 2020

(C) Société Internationale de Chirurgie 2020

\section{Dear Editor,}

We read with interest the manuscript of Naples and coworkers [1], about the significance of the splenectomy in the case of idiopathic splenomegaly. In Table 2, the authors show that $50 \%$ of patients were affected by benign diseases. This diagnosis has been reached postoperatively after definitive pathological examination of the spleen. We accept as the authors stated that this method is useful for the diagnosis of unclear splenomegaly, but splenectomy represents for the rest of the life the establishment of a lifetime risk for OPSI, especially for patients with benign disease. The initial tentative of diagnosis can be performed intraoperatively; if the diagnosis can be stated to conclusively be, for sure, benign, in this case, a spleen autotransplantation can be considered. After splenectomy for splenomegaly in case of the absence of malignancy, this procedure spleen autotransplantation, as suggested for trauma, can help maintain immunity and protect the patients for the rest of their life [2].

\section{References}

1. Naples R, Bertke A, Fafaj A et al (2020) The diagnostic utility of splenectomy in idiopathic splenomegaly. World J Surg 44:2959-2964

2. Toro A, Parrinello NL, Schembari E et al (2020) Single segment of spleen autotransplantation, after splenectomy for trauma, can restore splenic functions. World J Emerg Surg 15:17

Publisher's Note Springer Nature remains neutral with regard to jurisdictional claims in published maps and institutional affiliations.
Isidoro Di Carlo

idicarlo@unict.it

1 Department of Surgical Sciences and Advanced Technologies "G.F. Ingrassia", Cannizzaro Hospital, General Surgery, University of Catania, Via Messina 829, 95126 Catania, Italy

2 General Surgery, Augusta Hospital, Syracuse, Italy 